\title{
Feasibility of WHO mhGAP-intervention guide in reducing experienced discrimination in people with mental disorders: a pilot study in a rural Kenyan setting
}

\author{
V. N. Mutiso ${ }^{1}$, K. Pike ${ }^{2}$, C. W. Musyimi ${ }^{1}$, T. J. Rebello ${ }^{2}$, A. Tele ${ }^{1}$, I. Gitonga ${ }^{1}$, G. Thornicroft ${ }^{3}$ and \\ D. M. Ndetei ${ }^{1,4 *}$ \\ ${ }^{1}$ Africa Mental Health Foundation, Nairobi, Kenya \\ 2 Global Mental Health Program, Columbia University, New York, USA \\ ${ }^{3}$ Institute of Psychiatry, King's College London, London, UK \\ ${ }^{4}$ Department of Psychiatry University of Nairobi, Keny
}

\begin{abstract}
Aims Stigma can have a negative impact on help-seeking behaviour, treatment adherence and recovery of people with mental disorders. This study aimed to determine the feasibility of the WHO Mental Health Treatment Gap Interventions Guidelines (mhGAP-IG) to reduce stigma in face-to-face contacts during interventions for specific DSM-IV/ICD 10 diagnoses over a 6-month period.
\end{abstract}

Methods This study was conducted in 20 health facilities across Makueni County in southeast Kenya which has one of the poorest economies in the country and has no psychiatrist or clinical psychologist. We recruited 2305 participants from the health facilities catchment areas that had already been exposed to community mental health services. We measured stigma using DISC-12 at baseline, followed by training to the health professionals on intervention using the WHO mhGAP-IG and then conducted a follow-up DISC-12 assessment after 6 months. Proper management of the patients by the trained professionals would contribute to the reduction of stigma in the patients.

Results There was 59.5\% follow-up at 6 months. Overall, there was a significant decline in 'reported/experienced discrimination' following the interventions. A multivariate linear mixed model regression indicated that better outcomes of 'unfair treatment' scores were associated with: being married, low education, being young, being self-employed, higher wealth index and being diagnosed with depression. For 'stopping self' domain, better outcomes were associated with being female, married, employed, young, lower wealth index and a depression diagnosis. In regards to 'overcoming stigma' domain; being male, being educated, employed, higher wealth index and being diagnosed with depression was associated with better outcomes.

Conclusions The statistically significant $(p<0.05)$ reduction of discrimination following the interventions by trained health professionals suggest that the mhGAP-IG may be a useful tool for reduction of discrimination in rural settings in low-income countries.

Received 16 March 2018; Accepted 28 April 2018; First published online 4 June 2018

Key words: Discrimination, mental health, mental illness stigma, primary care.

\section{Introduction}

Stigma and discrimination can have a negative impact on help-seeking behaviour, treatment adherence and the recovery of people with mental disorders (Perlick et al. 2001; Barney et al. 2006; Gulliver et al. 2010). For purposes of cross country and cross LIMC and HIC comparisons, the Discrimination and Stigma Scale

*Address for correspondence: David Ndetei, Department of Psychiatry, Africa Mental Health Foundation, Nairobi, Nairobi, Kenya.

(Email: dmndetei@amhf.or.ke)
(DISC-12) was developed as a tool to measure discrimination as experienced by people with mental disorders in four main domains: perceived unfair (negative) treatment by others because of mental illness; stopping oneself from socio-economic participation; efforts to overcome stigma; and positive treatment by others (Thornicroft et al. 2009; Brohan et al. 2013; Koschorke et al. 2014).

A meta-analysis of randomised controlled trials (Griffiths et al. 2014) found educational interventions and contact (face-to-face) were effective in reducing stigma $(p<0.001)$ while there was no difference between face-to-face contact and internet programs. 
A global literature review (Thornicroft et al. 2016), concluded that social contact was the most effective type of intervention to improve stigma-related knowledge and attitudes in the short-term and also concluded that the evidence for the long-term benefit of such social contact was largely absent.

The World Health Organization (W.H.O), with a focus on LMICs has called for strategies to reduce stigma toward mental illnesses (Saxena et al. 2014) while the mhGAP-IG (W.H.O., 2010) provides practical steps for face-to-face contacts in addressing stigma. This Kenyan pilot study aimed to determine the feasibility of the WHO mhGAP-IG to reduce stigma in face-to-face contacts during interventions for specific DSM-IV/ICD 10 diagnoses over a 6-month period.

\section{Methods}

\section{The study site}

This study was conducted in Makueni County, one of the 47 counties in Kenya. It has one of the poorest economies in Kenya (Government of Makueni County, 2017). It has no psychiatrist or clinical psychologist. It has the following health facilities: one referral hospital, six sub-county hospitals, 21 health centers, 113 dispensaries and 11 private clinics (Makueni County, 2018). In consultation with the county officials, five dispensaries, nine health centers, five subcounty hospitals and the county referral hospital were selected as study sites. Clinicians (nurses and clinical officers), Community health workers (CHWs) attached to those facilities and Faith healers (FHs) or Traditional healers (THs) operating in the study catchment areas were approached and recruited by the research team. Community members, families and friends were engaged at community meetings, religious gatherings and in line at the health facilities. The engagements were interactive, with dialogue on benefits of good mental health, existing barriers and potential solutions to access mental health services and how to increase their access to mental health services.

\section{Assessment tools}

1. A researcher-designed socio-demographic and a wealth index questionnaire adopted from the World Bank International wealth index (Smits \& Steendijk, 2015) was administered at baseline. For the purposes of this study, we used factor scores derived from Principal Component Analysis (PCA) as the weights of items in its asset index (Vyas \& Kumaranayake, 2006). The availability of electricity in the home, ownership of items (refrigerator, TV, bicycle, motorcycle, mobile phone, radio and motor vehicle); how food is cooked in their house (gas stove, kerosene stove, electric stove, charcoal and wood) the type of residence (tenant, own house, stay with family and other) and the wall material in their residence (mud, plastered mud, iron sheets, wood and brick/stone) were used in constructing each participant's wealth index. The wealth index is divided into 5 quintiles to reflect relative levels of economic status.

2. The MINI-Plus: This is a researcher administered instrument for DSM-IV/ICD10 diagnoses. It can be administered by a trained lay person, who reads the questions up to 3 times and records the answers. It has good psychometric properties (Sheehan et al. 1997) and has been validated and used in LMICs (Akena et al. 2012; Nakimuli-Mpungu et al. 2012; van Heyningen et al. 2016) including Kenya by the same authors (Mutiso et al. 2017). We used it as a confirmatory diagnosis on those participants who were referred on screening positive on mhGAP-IG.

3. The Discrimination and Stigma Scale (DISC): The DISC-12 is a 34 item interview-based measure with good psychometric properties including interrater reliability (weighted kappa range: 0.62-0.95), internal consistency $(\alpha=0.78)$ and test-retest reliability (weighted kappa range: 0.56-0.89) (Brohan et al. 2013) with both quantitative and qualitative measures and has been used in LMICs (Brohan et al. 2013; Koschorke et al. 2014). The qualitative aspect asks respondents to give an example in each of the areas examined. The DISC was administered by a trained research assistant on a face-to-face basis immediately before the WHO mhGAP-IG clinical intervention and repeated 6 months later.

The instruments were adapted for Makueni County by convening a meeting of key stakeholders and individuals with relevant experience. The meeting comprised a psychiatrist, clinical psychologists, a public health physician, nurses, medical anthropologists, sociologists and residents from Makueni County who were conversant and fluent in the Kamba language. The team went through each tool, ensuring terminologies used were culturally appropriate. The mental health specialists ensured the meaning was not changed. The adaptation was through the dialogue until a consensus emerged.

\section{Participants}

Patients in the 20 study catchment areas who had been screened by trained traditional healers, faith healers, nurses, clinical officers, community health workers, family and friends; and referred to the nearest health 
facility where they underwent confirmatory diagnosis for DSM-IV/ICD 10 using the MINI-Plus. The MINI-Plus was administered by independent trained research assistants. Those who screened positive were approached for this study and those who gave informed consent were recruited for the confirmatory diagnosis.

\section{The intervention}

We used the WHO mhGAP-IG manual for intervention. This was done using the following steps: (i) The mhGAP-IG was adapted to fit the local context (See the appendix for details of the adaptation process). (ii) Several 1-hour community education sessions were conducted to enhance mental health knowledge and awareness in the catchment communities of the 20 facilities. These sessions were based on the adapted mhGAP-IG and covered the eight priority MNS conditions. The talks were designed to create awareness of the symptoms of the selected mental and neurological conditions, provide information on where they could get treatment for the disorders and educate on stigma and discrimination. The process was interactive with sessions on mental illnesses, specific symptomatology, causes and available treatments and prognoses. We informed them to go to their primary health care providers if they suspected they had a mental disorder based on the awareness talks. The awareness sessions were conducted by a team from Africa Mental Health Foundation (AMHF) composed of a clinical psychologist as the team leader in the field, two graduate nurses and a family physician. They all had been trained for this study by a psychiatrist (DMN) at AMHF.(iii) The adapted mhGAP-IG manual provided the framework for 5 full days of residential training for three subgroups: (1) FHs and THs, (2) CHWs and interested community members and (3) clinicians. The training was conducted by a clinical psychologist, a primary care physician and a nurse. The training covered each of the symptoms of the adult disorders from the mhGAP-IG. Teaching methods included PowerPoint presentations, case discussions combined with small group activities, mock screenings and referral processes. Providers were also trained in using the mhGAP-IG as a screening tool, going through the checklist of symptoms with patients who agreed to be screened. Patients who screened positive were referred to one of the 20 study sites. Overall, 40 clinicians, $60 \mathrm{CHWs}, 51 \mathrm{FHs}$ and 59 THs (total $N=210$ ) were trained.(iv) Clinicians received additional training on using mhGAP-IG to offer psychosocial and biological interventions to participants who had screened positive for any of the priority mental illnesses. These illnesses are; depression, schizophrenia and other psychotic disorders, suicide, epilepsy, dementia, disorders due to use of alcohol and disorders due to use of illicit drugs. Our study only involved adults and therefore mental disorders in children were excluded. The interventions were delivered based on the mhGAP-IG manual which included pharmacological, psychological and psychosocial or both depending on the condition. Psychosocial and psychosocial interventions were interpersonal, informational activities which included psychoeducation on symptom recognition, prevention and coping strategies and stigma reduction. They also involved life skills training and better health-seeking behaviours. Pharmacological interventions involved giving the psychotropic medications. These interventions targeted biological, behavioural, cognitive, emotional and environmental factors with the aim of improving the psychological health and overall well-being. On average the mhGAP-IG prescribed intervention took between 10 and 20 minutes. Alongside treatment and care, every intervention, irrespective of the condition the participant had screened positive for, included psychoeducation and mental health advocacy. Advocacy is the use of information in deliberate and strategic ways to influence others to create change. It involves the promotion of the needs and rights of people with mental disorders, as well as that of the general population.

\section{Data analysis}

Descriptive statistics were generated for all the variables in the dataset. Paired sample $t$-test was used to determine whether there was a significant difference between the pre- and post-intervention on each of the four sub-scales as well as the total scores. The nature of associations between discrimination and stigma scores and the independent variables was analysed using the generalised linear mixed model. To study the adjusted associations between risk factors and discrimination/stigma scores, we developed multivariate-adjusted linear mixed models with sociodemographic characteristics as fixed effects and time as both fixed and random effect. Scores of participants who were lost to follow-ups were imputed using five randomly generated scores based on their baseline DISC scores, gender, age, marital status, level of education, employment status, wealth index and the type diagnosis at baseline. Sensitivity analysis was done using complete cases only. All the analysis were done by STATA version 14 .

\section{Results}

All 2305 patients who consented to participate in the study completed the pre-intervention survey. Of 
these 2305 participants, 1372 completed the postintervention survey 6 months after the intervention The follow-up rates ranged from 46.2 to $69 \%$, with an average of $59.5 \%$, depending on various sociodemographic characteristics and clinical diagnoses as summarised in Table 1.

Table 2 summarises the outcomes of the items on DISC-12 and Table 3 summarises the outcomes of the DISC-12 domains while Figs 1 and 2 gives a graphic visualisation of Table 2.

In general, there was a reduction in the proportion of those participants reporting unfair treatment in all the 22 items of the domain (Table 2). The higher percentage was recorded on discrimination stemming from sources closer to the participants (e.g. by neighbours, family, housing). There was a significant reduction in unfair treatment scores after the intervention (mean difference 0.62; $p<0.001$ (Table 3).

Table 4 summarises the outcomes after adjusting for other covariates. Participants who were either widowed/separated or divorced had significantly worse outcomes as compared with those who were married $(p<0.001)$. Those with no formal education had better outcomes as compared with those with primary education, secondary education and tertiary education; as the level of education increased, participants had worse outcomes as compared with those with no formal education $(p<0.001)$.

Those who were self-employed had better outcomes as compared with those who with formal employment and unemployed $(p<0.001)$. Participants aged 20 years and below had better outcomes as compared with

Table 1. Socio-demographic characteristics of the participants

\begin{tabular}{|c|c|c|c|c|}
\hline Variable & Category & $\begin{array}{c}\text { Pretest }(N=2305) \\
n(\%)\end{array}$ & $\begin{array}{c}\text { Posttest }(N=1372) \\
n(\%)\end{array}$ & $\begin{array}{c}\text { Follow-up rate } \\
\qquad(\%)\end{array}$ \\
\hline \multirow[t]{2}{*}{ Gender } & Female & $1531(66.4)$ & $925(67.4)$ & 60.4 \\
\hline & Male & $774(33.6)$ & 447 (32.6) & 57.8 \\
\hline \multirow[t]{3}{*}{ Marital status } & Married & $1445(62.7)$ & $911(66.4)$ & 63.0 \\
\hline & Single/never married & $391(17.0)$ & $210(15.3)$ & 53.7 \\
\hline & Widowed/divorced/separated & $469(20.3)$ & $251(18.3)$ & 53.5 \\
\hline \multirow[t]{5}{*}{ Education level } & No formal education & $529(23.0)$ & $332(24.2)$ & 62.8 \\
\hline & Primary education & $1359(59.0)$ & $809(59.0)$ & 59.5 \\
\hline & Secondary education & $351(15.2)$ & $193(14.1)$ & 55.0 \\
\hline & Tertiary/university education & $65(2.8)$ & $37(2.7)$ & 56.9 \\
\hline & Missing & $1(0.0)$ & $1(0.1)$ & \\
\hline \multirow[t]{4}{*}{ Employment status } & Self-employed & $873(37.9)$ & $602(43.9)$ & 69.0 \\
\hline & Employed & $523(22.7)$ & $310(22.6)$ & 59.3 \\
\hline & Unemployed & $905(39.3)$ & $458(33.4)$ & 50.6 \\
\hline & Missing & $4(0.2)$ & $2(0.1)$ & \\
\hline \multirow[t]{6}{*}{ Age } & 20 and below & $47(2.0)$ & $30(2.2)$ & 63.8 \\
\hline & 21-30 years & $329(14.3)$ & $182(13.3)$ & 55.3 \\
\hline & $31-40$ years & $396(17.2)$ & $236(17.2)$ & 59.6 \\
\hline & $41-50$ years & $357(15.5)$ & $219(16.0)$ & 61.3 \\
\hline & $51-60$ years & $397(17.2)$ & $241(17.6)$ & 60.7 \\
\hline & 60 and above & $779(33.8)$ & $464(33.8)$ & 59.6 \\
\hline \multirow[t]{5}{*}{ Wealth index } & Quintile 1 & $401(17.4)$ & $257(18.7)$ & 64.1 \\
\hline & Quintile 2 & $386(16.7)$ & $207(15.1)$ & 53.6 \\
\hline & Quintile 3 & $481(20.9)$ & $283(20.6)$ & 58.8 \\
\hline & Quintile 4 & $446(19.3)$ & $258(18.8)$ & 57.8 \\
\hline & Quintile 5 & $591(25.6)$ & $367(26.7)$ & 62.1 \\
\hline \multirow[t]{9}{*}{ Diagnosis } & Major depression & $886(38.4)$ & $593(43.2)$ & 66.9 \\
\hline & Suicide & $26(1.1)$ & $12(0.9)$ & 46.2 \\
\hline & Mania/hypomania & $19(0.8)$ & $10(0.7)$ & 52.6 \\
\hline & Alcohol dependence/abuse & $102(4.4)$ & $64(4.7)$ & 62.7 \\
\hline & Substance abuse/dependence & $40(1.7)$ & $24(1.7)$ & 60.0 \\
\hline & Psychosis & $85(3.7)$ & $43(3.1)$ & 50.6 \\
\hline & Cognitive deficit & $392(17.0)$ & $240(17.5)$ & 61.2 \\
\hline & Epilepsy & $166(7.2)$ & $108(7.9)$ & 65.1 \\
\hline & Comorbid & $589(25.6)$ & $278(20.3)$ & 47.2 \\
\hline
\end{tabular}


Table 2. Proportion of agree responses for DISC items before and after intervention

\begin{tabular}{|c|c|c|c|}
\hline $\begin{array}{l}\text { Question } \\
\text { Have you...... }\end{array}$ & $\begin{array}{c}\text { Before } \\
(N=1372)^{\mathrm{a}} \\
n(\%)\end{array}$ & $\begin{array}{c}\text { After } \\
(N=1372) \\
n(\%)\end{array}$ & $\begin{array}{c}\% \\
\text { Change }\end{array}$ \\
\hline 1. Been treated unfairly in making or keeping friends (UT) & $58(4.2)$ & $8(0.6)$ & $3.6^{* * *}$ \\
\hline 2. Been treated unfairly by the people in your neighbourhood(UT) & $176(12.8)$ & $47(3.4)$ & $9.4^{* * *}$ \\
\hline 3. Been treated unfairly in dating or intimate relationships (UT) & $93(6.8)$ & $14(1.0)$ & $5.8^{* * *}$ \\
\hline 4. Been treated unfairly in housing (UT) & $98(7.1)$ & $9(0.7)$ & $6.5^{* * *}$ \\
\hline 5. Been treated unfairly in your education (UT) & $29(2.1)$ & $2(0.1)$ & $2.0^{* * *}$ \\
\hline 6. Been treated unfairly in marriage or divorce (UT) & $121(8.8)$ & $27(2.0)$ & $6.9^{* * *}$ \\
\hline 7. Been treated unfairly by your family (UT) & $155(11.3)$ & $68(5.0)$ & $6.3^{* * *}$ \\
\hline 8. Been treated unfairly in finding a job (UT) & $40(2.9)$ & $10(0.7)$ & $2.2^{* * *}$ \\
\hline 9. Been treated unfairly in keeping a job (UT) & $41(3.0)$ & $7(0.5)$ & $2.5^{* * *}$ \\
\hline 10. Been treated unfairly when using public transport (UT) & $34(2.5)$ & $3(0.2)$ & $2.3^{* * *}$ \\
\hline 11. Been treated unfairly in getting welfare benefits or disability pensions (UT) & $75(5.5)$ & $12(0.9)$ & $4.6^{* * *}$ \\
\hline 12. Been treated unfairly in your religious practices (UT) & $11(0.8)$ & $2(0.1)$ & $0.7^{* *}$ \\
\hline 13. Been treated unfairly in your social life (UT) & $92(6.7)$ & $10(0.7)$ & $6.0^{* * *}$ \\
\hline 14. Been treated unfairly by the police (UT) & $31(2.3)$ & $6(0.4)$ & $1.8^{* * *}$ \\
\hline 15. Been treated unfairly when getting help for physical health problems (UT) & $3(0.2)$ & $1(0.1)$ & $0.1^{\mathrm{n} / \mathrm{s}}$ \\
\hline 16. Been treated unfairly by mental health staff (UT) & $2(0.1)$ & $1(0.1)$ & $0.1^{\mathrm{n} / \mathrm{s}}$ \\
\hline 17. Been treated unfairly in your levels of privacy (UT) & $13(0.9)$ & $3(0.2)$ & $0.7^{* *}$ \\
\hline 18. Been treated unfairly in your personal safety and security (UT) & $46(3.4)$ & $7(0.5)$ & $2.8^{* * *}$ \\
\hline 19. Been treated unfairly in starting a family or having children (UT) & $23(1.7)$ & $2(0.1)$ & $1.5^{* * *}$ \\
\hline 20. Been treated unfairly in your role as a parent to your children (UT) & $62(4.5)$ & $16(1.2)$ & $3.4^{* * *}$ \\
\hline $\begin{array}{l}\text { 21. Been avoided or shunned by people who know that you have a mental } \\
\text { health problem (UT) }\end{array}$ & $62(4.5)$ & $29(2.1)$ & $2.4^{* * *}$ \\
\hline 22. Been treated unfairly in any other areas of life (UT) & $50(3.6)$ & $8(0.6)$ & $3.1^{* * *}$ \\
\hline 23. Stopped yourself from applying for work (SS) & $134(9.8)$ & $82(6.0)$ & $3.8^{* * *}$ \\
\hline 24. Stopped yourself from applying for education or training courses (SS) & $153(11.2)$ & $131(9.5)$ & $1.6^{\mathrm{n} / \mathrm{s}}$ \\
\hline 25. Stopped yourself from having a close personal relationship (SS) & $46(3.4)$ & $12(0.9)$ & $2.5^{* * *}$ \\
\hline 26. Concealed or hidden your mental health problem from others (SS) & $72(5.2)$ & $29(2.1)$ & $3.1^{* * *}$ \\
\hline 27. Made friends with people who don't use mental health services (OS) & $658(48.0)$ & $813(59.3)$ & $-11.3^{* * *}$ \\
\hline $\begin{array}{l}\text { 28. Been able to Use your personal skills or abilities in coping with stigma and } \\
\text { discrimination (OS) }\end{array}$ & $311(22.7)$ & $279(20.3)$ & $2.3^{*}$ \\
\hline 29. Been treated More positively by your family (PT) & $866(63.1)$ & $913(66.5)$ & $-3.4^{* *}$ \\
\hline 30. Been treated More positively in getting welfare benefits or disability pensions (PT) & $122(8.9)$ & $59(4.3)$ & $4.6^{* * *}$ \\
\hline 31. Been treated More positively in housing $(\mathrm{PT})$ & $834(60.8)$ & $852(62.1)$ & $-1.3^{\mathrm{n} / \mathrm{s}}$ \\
\hline 32. Been treated More positively in your religious activities (PT) & $767(55.9)$ & $731(53.3)$ & $2.6^{*}$ \\
\hline 33. Been treated More positively in employment (PT) & $298(21.7)$ & $204(14.9)$ & $6.9^{* * *}$ \\
\hline 34. Been treated More positively in any other areas of life (PT) & $251(18.3)$ & $115(8.4)$ & $9.9^{* * *}$ \\
\hline
\end{tabular}

UT, unfair treatment subscale; SS, stopping self subscale; OS, overcoming stigma subscale; PT, positive treatment; MHP, mental health problem.

${ }^{* * *} p<0.001 ; * * p<0.01 ; p<0.05^{\mathrm{n} / \mathrm{s}}$ not significant.

${ }^{a}$ Complete cases, Pre and post DISC.

those aged above 20 years. Participants who were grouped in the higher wealth index (quintiles 4 and 5) had better outcomes as compared with those in quintile 1 . Figure 1 displays changes in individual questions on "stopping self" domain before and after the intervention. Overall there was a reduction in all the items after the intervention. With regard to score, there was a significant decrease in stopping self-scores after intervention (Table 3; mean difference 0.08, $p<0.001)$. Controlling for other variables, females had better outcomes as compared with males. Those who were married had better outcomes as compared with those who were single. Participants who were unemployed had worse outcomes as compared with those who were self-employed. Participants who were aged 20 years and below had better outcomes as compared with those aged 21 years and above. Those in the lowest wealth index quintile had better 
Table 3. Changes in DISC scores before intervention and after intervention

\begin{tabular}{|c|c|c|c|c|c|c|c|}
\hline \multirow[b]{2}{*}{ Variable } & \multicolumn{2}{|c|}{ Before } & \multicolumn{2}{|c|}{ After } & \multirow[b]{2}{*}{ Mean change (S.D.) } & \multirow[b]{2}{*}{ Effect size $^{a}$} & \multirow[b]{2}{*}{$p$-value ${ }^{\mathrm{b}}$} \\
\hline & Mean (S.D.) & Min-Max & Mean (S.D.) & Min-Max & & & \\
\hline DISC total $\operatorname{count}^{\mathrm{c}}(N=2305)$ & $4.40(3.59)$ & $0-25$ & $3.43(2.23)$ & $0-22$ & $0.98(3.00)$ & 0.33 & $<0.001$ \\
\hline DISC unfair treatment & $1.08(2.13)$ & $0-16$ & $0.46(0.81)$ & $0-15$ & $0.62(2.08)$ & 0.39 & $<0.001$ \\
\hline DISC stopping self & $0.27(0.65)$ & $0-4$ & $0.31(0.47)$ & $0-3$ & $-0.04(0.69)$ & 0.07 & 0.006 \\
\hline DISC overcoming stigma & $0.77(0.78)$ & $0-2$ & $0.83(0.61)$ & $0-2$ & $-0.07(0.76)$ & 0.09 & $<0.001$ \\
\hline DISC positive treatment & $2.29(1.89)$ & $0-6$ & $2.19(1.55)$ & $0-6$ & $0.10(1.35)$ & 0.06 & $<0.001$ \\
\hline DISC total mean ${ }^{\mathrm{d}}$ & $0.59(0.47)$ & $0-1.9$ & $0.56(0.35)$ & $0-1.5$ & $0.03(0.37)$ & 0.09 & $<0.001$ \\
\hline DISC unfair treatment & $0.12(0.24)$ & $0-1.9$ & $0.04(0.08)$ & $0-1.3$ & $0.07(0.23)$ & 0.45 & $<0.001$ \\
\hline DISC stopping self & $0.18(0.45)$ & $0-3.0$ & $0.19(0.30)$ & $0-2.3$ & $-0.01(0.47)$ & 0.03 & 0.440 \\
\hline DISC overcoming stigma & $1.00(1.06)$ & $0-3.0$ & $1.16(0.85)$ & $0-3.0$ & $-0.16(1.05)$ & 0.17 & $<0.001$ \\
\hline DISC positive treatment & $1.07(0.90)$ & $0-3.0$ & $1.02(0.74)$ & $0-3.0$ & $0.05(0.64)$ & 0.06 & 0.001 \\
\hline DISC total count $(\mathrm{N}=1372)$ & $4.25(3.58)$ & $0-25$ & $3.29(2.32)$ & $0-22$ & $0.96(2.91)$ & 0.32 & $<0.001$ \\
\hline DISC unfair treatment ${ }^{\mathrm{e}}$ & $0.96(2.05)$ & $0-16$ & $0.21(0.85)$ & $0-15$ & $0.75(1.99)$ & 0.48 & $<0.001$ \\
\hline DISC stopping self ${ }^{\mathrm{e}}$ & $0.30(0.68)$ & $0-4$ & $0.19(0.51)$ & $0-3$ & $0.11(0.70)$ & 0.18 & $<0.001$ \\
\hline DISC overcoming stigma ${ }^{\mathrm{e}}$ & $0.71(0.77)$ & $0-2$ & $0.80(0.67)$ & $0-2$ & $-0.09(0.76)$ & 0.13 & $<0.001$ \\
\hline DISC positive treatment ${ }^{\mathrm{e}}$ & $2.29(1.85)$ & $0-6$ & $2.09(1.62)$ & $0-6$ & $0.19(1.31)$ & 0.12 & $<0.001$ \\
\hline DISC total mean ${ }^{\mathrm{e}}$ & $0.57(0.48)$ & $0-1.9$ & $0.55(0.37)$ & $0-1.5$ & $0.03(0.37)$ & 0.05 & 0.013 \\
\hline DISC unfair treatment ${ }^{\mathrm{e}}$ & $0.10(0.23)$ & $0-1.9$ & $0.02(0.08)$ & $0-1.3$ & $0.08(0.08)$ & 0.46 & $<0.001$ \\
\hline DISC stopping self ${ }^{\mathrm{e}}$ & $0.20(0.47)$ & $0-3.0$ & $0.12(0.33)$ & $0-2.3$ & $0.08(0.33)$ & 0.20 & $<0.001$ \\
\hline DISC overcoming stigma ${ }^{\mathrm{e}}$ & $0.91(1.03)$ & $0-3.0$ & $1.09(0.92)$ & $0-3.0$ & $-0.17(0.92)$ & 0.18 & $<0.001$ \\
\hline DISC positive treatment ${ }^{\mathrm{e}}$ & $1.07(0.88)$ & $0-3.0$ & $0.96(0.78)$ & $0-3.0$ & $0.11(0.78)$ & 0.13 & $<0.001$ \\
\hline
\end{tabular}

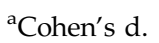

${ }^{b}$ Paired samples t-test.

'DISC total count is the count of the number of items endorsed in the DISC scale or subscale.

${ }^{\mathrm{d}}$ DISC total mean is the mean DISC scale or a subscale score.

ésensitivity analysis for complete cases only.

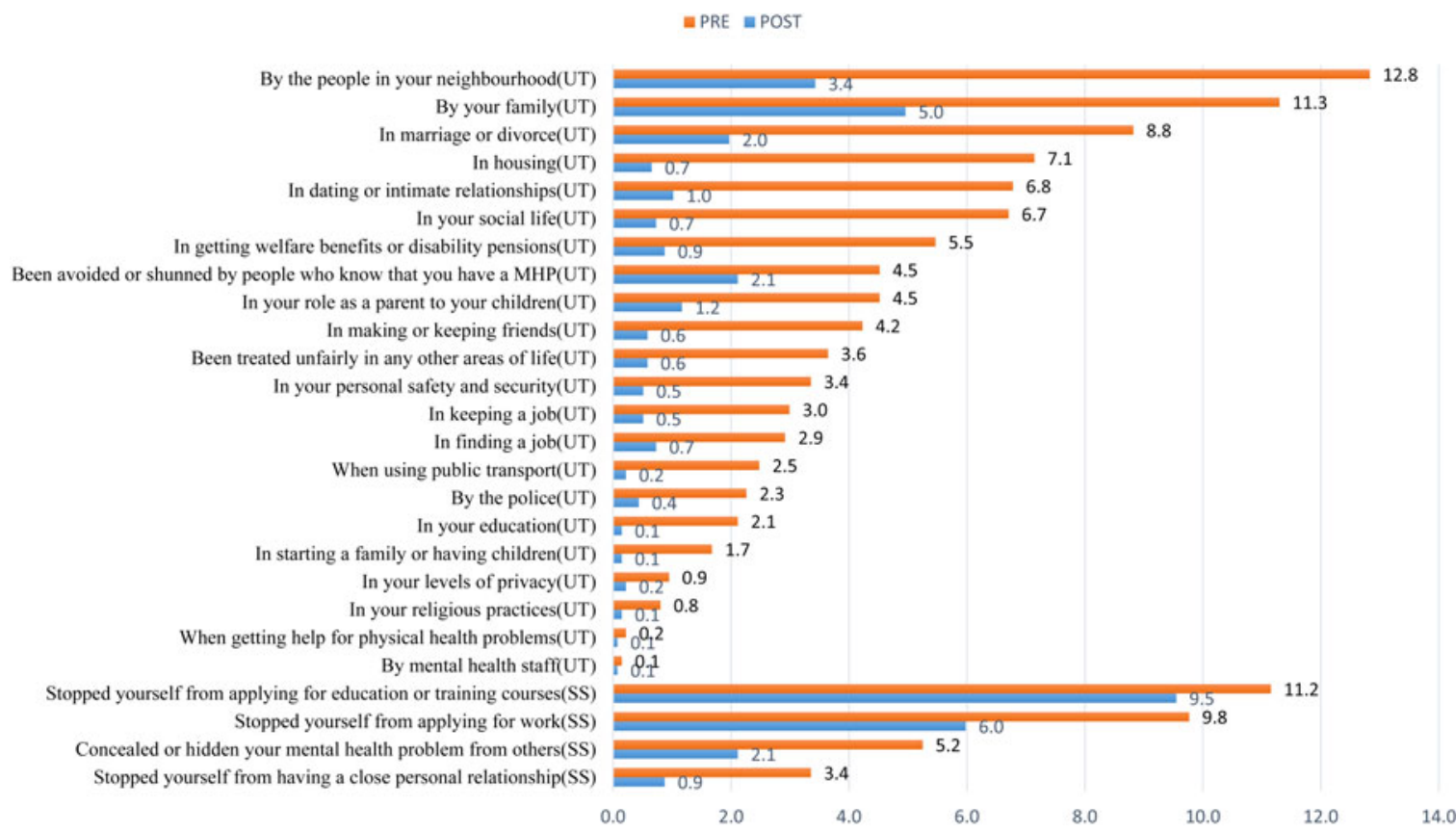

Fig. 1. Negative discrimination and stopping self-item percentages; Note-UT-unfair treatment 'Have you ever been treated unfairly.......'; SS-stopping self 'Have You.....'MHP-mental health problem. 


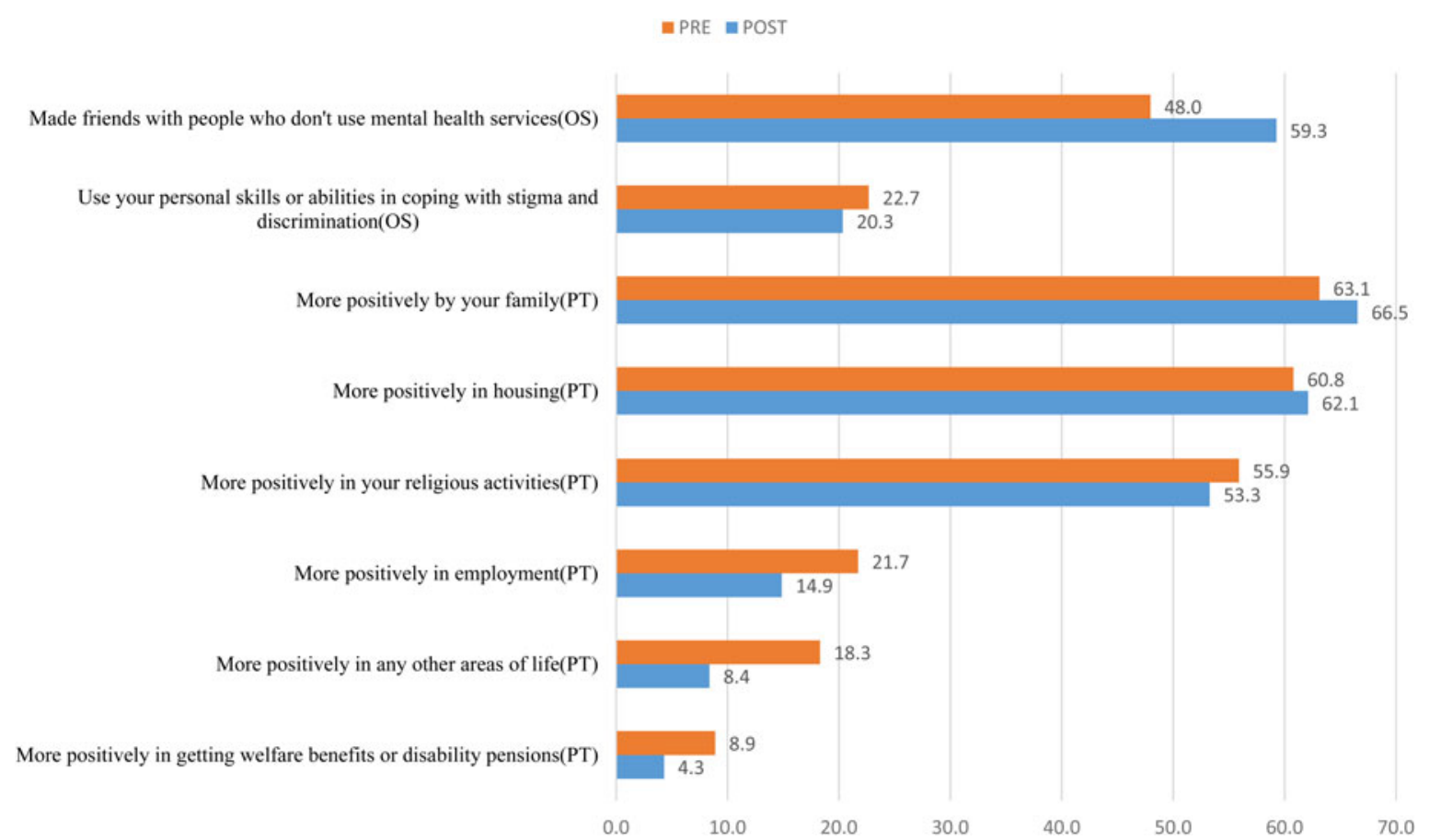

Fig. 2. Overcoming stigma (OS)'Have you ....'and positive treatment (PT) item Percentages 'Have you been treated......'.

outcomes as compared with those in quintile 3. Participants diagnosed with major depression had better outcomes as compared with those diagnosed with epilepsy, psychosis, mania/hypomania, alcohol abuse and suicidality. No significant differences were found between depression and dementia, substance abuse and co-morbid disorders.

Figure 2 displays changes in individual questions on 'overcoming discrimination' domain before and after the intervention. Overall there was a significant increase in overcoming stigma scores after the intervention (Table 3 ; mean difference $=0.17 ; p<0.001$ ). Males had better outcomes as compared with females. Those with a primary level of education and higher had better outcomes than those with no formal education. Those who were employed had better outcomes as compared with those who were self-employed. Those who had wealth index of quintile 3 and above had better outcomes than those with wealth index of quintile 1 . There were no significant differences between wealth index quintiles 1 and 2 . The participants who were diagnosed with hypomania/mania, psychosis and epilepsy had better outcomes as compared with those diagnosed with the major depressive disorder, however, those diagnosed with substance abuse and dementia had worse outcomes as compared with those diagnosed with the major depressive disorder.

The changes in positive treatment items before and after intervention are shown in Fig. 2. There was an increase in the proportion of the participants who reported to have been treated more positively by their family members from 63.1 to $66.5 \%$ and more positively in housing from 60.8 to $62.1 \%$; however, there was a reduction in the proportion of participants reporting being treated more positively in religious activities, employment, other areas of life and in getting welfare benefits or disability pensions after the intervention. Overall, there was a significant decrease in positive treatment scores after the intervention (Table 3; mean difference $=0.11 ; p<0.001$ ) .

Participants who were diagnosed with major depression had better outcomes in negative discrimination domain (unfair treatment) as compared with those diagnosed with suicide, psychosis and a comorbid disorder. They also had better outcomes in the stopping-self domain as compared with those diagnosed with epilepsy, psychosis, mania/hypomania, alcohol abuse and suicide. However, the participants who were diagnosed with mania/hypomania, psychosis, and epilepsy had better outcomes in the overcoming stigma domain as compared with those diagnosed with the major depressive disorder. In contrast, those diagnosed with substance abuse and cognitive defects had overall worse outcomes as compared with those diagnosed with the major depressive disorder in the overcoming stigma domain. Even though there was a significant reduction in the positive treatment domain, participants who were diagnosed with alcohol abuse, substance abuse, cognitive defects and comorbid disorders had better outcomes as compared 
Table 4. Socio-demographic factors associated with the change in DISC domains counts after interventions

\begin{tabular}{|c|c|c|c|c|c|c|c|c|c|}
\hline \multirow[b]{2}{*}{ Parameter } & \multirow[b]{2}{*}{ Category } & \multicolumn{2}{|c|}{ Unfair treatment } & \multicolumn{2}{|c|}{ Stopping self } & \multicolumn{2}{|c|}{ Overcoming stigma } & \multicolumn{2}{|c|}{ Positive treatment } \\
\hline & & Est(S.E) & $p$-Value & Est(S.E) & $p$-Value & Est(S.E) & $p$-Value & Est(S.E) & $p$-Value \\
\hline \multirow[t]{2}{*}{ Gender } & Female $^{\mathrm{a}}$ & & & & & & & & \\
\hline & Male & $-0.08(0.06)$ & 0.151 & $0.07(0.03)$ & 0.018 & $0.07(0.03)$ & 0.008 & $0.28(0.07)$ & $<0.001$ \\
\hline \multirow{3}{*}{ Marital Status } & Married $^{\mathrm{a}}$ & & & & & & & & \\
\hline & Single/Never married & $0.13(0.08)$ & 0.130 & $0.17(0.04)$ & $<0.001$ & $-0.03(0.04)$ & 0.510 & $0.02(0.11)$ & 0.845 \\
\hline & Others ${ }^{b}$ & $0.49(0.07)$ & $<0.001$ & $0.02(0.03)$ & 0.464 & $0.03(0.03)$ & 0.285 & $-0.15(0.08)$ & 0.072 \\
\hline \multirow[t]{4}{*}{ Education level } & No formal education ${ }^{\mathrm{a}}$ & & & & & & & & \\
\hline & Primary education & $0.30(0.07)$ & $<0.001$ & $0.04(0.03)$ & 0.301 & $0.11(0.03)$ & 0.001 & $-0.31(0.09)$ & 0.001 \\
\hline & Secondary education & $0.38(0.10)$ & $<0.001$ & $0.00(0.05)$ & 0.990 & $0.19(0.05)$ & $<0.001$ & $-0.02(0.12)$ & 0.854 \\
\hline & Tertiary & $0.54(0.17)$ & 0.001 & $0.12(0.08)$ & 0.160 & $0.30(0.08)$ & $<0.001$ & $0.28(0.21)$ & 0.183 \\
\hline \multirow[t]{3}{*}{ Employment Status } & Self-Employed ${ }^{\mathrm{a}}$ & & & & & & & & \\
\hline & Employed & $0.25(0.07)$ & $<0.001$ & $-0.04(0.03)$ & 0.2590 & $0.09(0.03)$ & 0.009 & $0.73(0.09)$ & $<0.001$ \\
\hline & Unemployed & $0.24(0.06)$ & $<0.001$ & $0.09(0.03)$ & 0.002 & $0.14(0.03)$ & $<0.001$ & $0.24(0.08)$ & 0.002 \\
\hline \multirow[t]{6}{*}{ Age } & 20 and below ${ }^{a}$ & & & & & & & & \\
\hline & $21-30$ years & $0.35(0.19)$ & 0.058 & $0.25(0.09)$ & 0.006 & $0.01(0.09)$ & 0.892 & $-0.05(0.23)$ & 0.834 \\
\hline & $31-40$ years & $0.45(0.19)$ & 0.019 & $0.32(0.09)$ & 0.001 & $-0.01(0.09)$ & 0.945 & $0.10(0.24)$ & 0.683 \\
\hline & $41-50$ years & $0.58(0.19)$ & 0.003 & $0.30(0.09)$ & 0.002 & $0.04(0.09)$ & 0.637 & $0.10(0.24)$ & 0.672 \\
\hline & $51-60$ years & $0.41(0.20)$ & 0.037 & $0.33(0.09)$ & $<0.001$ & $0.02(0.09)$ & 0.869 & $0.16(0.25)$ & 0.513 \\
\hline & 60 and above & $0.48(0.20)$ & 0.013 & $0.40(0.09)$ & $<0.001$ & $0.17(0.09)$ & 0.068 & $0.51(0.24)$ & 0.036 \\
\hline \multirow[t]{5}{*}{ Wealth index } & Quintile $1^{\mathrm{a}}$ & & & & & & & & \\
\hline & Quintile 2 & $-0.11(0.09)$ & 0.219 & $0.03(0.04)$ & 0.528 & $0.00(0.04)$ & 0.934 & $-0.35(0.11)$ & 0.001 \\
\hline & Quintile 3 & $-0.03(0.08)$ & 0.715 & $0.11(0.04)$ & 0.007 & $0.08(0.04)$ & 0.041 & $0.13(0.10)$ & 0.191 \\
\hline & Quintile 4 & $-0.16(0.08)$ & 0.049 & $0.00(0.04)$ & 0.905 & $0.14(0.04)$ & $<0.001$ & $-0.01(0.10)$ & 0.919 \\
\hline & Quintile 5 & $-0.25(0.08)$ & 0.003 & $0.04(0.04)$ & 0.339 & $0.12(0.04)$ & 0.003 & $-0.81(0.10)$ & $<0.001$ \\
\hline \multirow[t]{9}{*}{ Diagnosis } & Major depression ${ }^{\mathrm{a}}$ & & & & & & & & \\
\hline & Suicide & $1.43(0.24)$ & $<0.001$ & $0.36(0.13)$ & 0.007 & $0.05(0.12)$ & 0.675 & $0.37(0.30)$ & 0.213 \\
\hline & Mania/Hypomania & $0.34(0.28)$ & 0.225 & $0.75(0.15)$ & $<0.001$ & $0.40(0.13)$ & 0.003 & $-0.02(0.35)$ & 0.956 \\
\hline & Alcohol dependence/abuse & $0.10(0.13)$ & 0.449 & $0.18(0.06)$ & 0.005 & $-0.07(0.06)$ & 0.283 & $-0.52(0.16)$ & 0.001 \\
\hline & Substance abuse/dependence & $0.04(0.20)$ & 0.851 & $-0.05(0.10)$ & 0.5850 & $-0.29(0.09)$ & 0.002 & $-1.05(0.24)$ & $<0.001$ \\
\hline & Psychosis & $0.74(0.14)$ & $<0.001$ & $0.42(0.07)$ & $<0.001$ & $0.18(0.07)$ & 0.008 & $0.42(0.17)$ & 0.015 \\
\hline & Dementia & $-0.06(0.08)$ & 0.418 & $0.06(0.04)$ & 0.076 & $-0.19(0.04)$ & $<0.001$ & $-0.30(0.09)$ & 0.001 \\
\hline & Epilepsy & $0.02(0.11)$ & 0.857 & $0.43(0.05)$ & $<0.001$ & $0.23(0.05)$ & $<0.001$ & $0.36(0.14)$ & 0.010 \\
\hline & Comorbid & $0.14(0.06)$ & 0.034 & $0.06(0.03)$ & 0.080 & $-0.01(0.03)$ & 0.726 & $-0.20(0.08)$ & 0.013 \\
\hline Time & Pre-Post & $-0.62(0.04)$ & $<0.001$ & $-0.11(0.02)$ & $<0.001$ & $0.07(0.02)$ & $<0.001$ & $-0.10(0.03)$ & $<0.001$ \\
\hline Intercept & Constant & $0.79(0.22)$ & $<0.001$ & $-0.14(0.10)$ & 0.167 & $0.37(0.10)$ & $<0.001$ & $2.36(0.27)$ & $<0.001$ \\
\hline
\end{tabular}

${ }^{a}$ Reference category; Est., estimate; S.E., standard error.

${ }^{\mathrm{b}}$ Divorced/Widowed/Separated. 
with those diagnosed with depression. However, those diagnosed with epilepsy and psychosis had worse outcomes as compared with those diagnosed with depression.

\section{Discussion}

\section{Socio-demographics}

The age structure found in this study does not reflect the pyramid structure typical of Kenyan demographics (Kenya National Bureau of Statistics, 2010). This study included adults aged 18 and above and therefore the very low percentage for age group 20 and below. Those 60 and above constituted a third of the respondents. We speculate that this age group took the highest interest in our study because they would be relatively available post-retirement. It is not surprising therefore that dementia/cognitive deficits were the second single common diagnosis after the depression.

\section{Follow-up rates}

We have plausible explanations based on our clinical experiences and past research findings for the observed follow-up rates. In one of our studies (Mendenhall et al. 2017), we have demonstrated that for different people 'recovery' is defined by several contextual and individual considerations. If the symptoms reduce to a level where they are not a priority compared with other life priorities such as pursuing economic activities to earn a living, saving the money used to travel to hospital, attend to other social activities or go for treatment concurrent physical illness etc., then they will consider themselves adequately recovered to pursue other more pressing life priorities (Mendenhall et al. 2017). This could partly explain the observed follow-up rates for different socio-demographic variables and diagnoses.

By and large, this study supports previous studies that found that contact (here defined as face to face) based interventions are effective. The effect size of the intervention ranged from 0.18 to 0.46 which is comparable with previous literature reviews (Corrigan et al. 2012; Griffiths et al. 2014; Thornicroft et al. 2016); the effect sizes of stigma reduction programs involving contact are between small to medium (0.29 and 0.47) (Cohen, 1988) which is similar to what we found in our study.

\section{The risk and protective factors}

We speculate several dynamics in the overall change across the several domains of the DISC- 12 .
Post-intervention the participants perceived less barrier between themselves and other people with no mental disorders; a positive reciprocal response from other people who saw improvement in them and therefore a gain in self-esteem; a better understanding of mental illness as biological conditions like any other conditions and less of cultural stigmatising explanations for their mental illness; and appreciation of their human rights like any other person; the clinical improvements about their conditions which enhanced their self-esteem. However, there were some unique responses that can be explained. Positive increase rather than decrease was reported in item $28(p<0.001)$; and decrease rather increase was reported in items 30, 32, $33 \& 3429(p<0.01)$. We speculate this was a reciprocal reaction of people who noticed a change in these people since the participants in this study were also receiving the clinical intervention. It is noteworthy that items $15,16,24$ and 31 were not associated with significant change $(p>0.05)$ between pre and post-test. We speculate that because these items did not involve a close emotional relationship with the stigmatised people and therefore stigma was felt less at a personal level.

When comparing changes in the sub-domains before after intervention, unfair treatment was particularly decreased, demonstrated by greater mean changes and effect size. This may indicate that negative discrimination/experiences of negative reactions play a major role in discrimination and stigma among people with mental illness in our study population.

Out of the 22 items of the unfair treatment domain the items with the greatest change was being treated unfairly in their neighbourhood, in marriage or divorce, in housing, by your family, in social life, in dating or intimate relationship and in getting welfare benefits or disability pensions. This suggests that stigma was most felt if it was associated with people who would otherwise be considered emotionally close and expected to play a greater role in being least discriminating and most accommodating.

Our findings across the four DISC-12 domains suggest overall significant improvement except in one: total mean for DISC stopping self. This is in agreement with what has been found in other studies that did not use mhGAP-IG (Corrigan et al. 2012; Griffiths et al. 2014; Thornicroft et al. 2016). The reduction in unfair treatment scores after the intervention was strongly associated with marital status. Those who were married had better outcomes as compared with those who are either divorced/separated or widowed confirming what was mentioned earlier that ongoing close relationships were critical to stigma reduction. Those with higher education experienced a lesser degree of decrease at post-test probably because they 
had a better understanding of mental illness (as described above) even before the interventions. Given that those with higher education had less scores at pretest, these participants had less room to improve their scores at post-test.

We attribute our finding that older adults had better outcomes as compared with younger adults to better reporting, which is in agreement with other studies (Ali et al. 2016). However, it is important to note that older patients may demonstrate other needs or risk factors for stigma and discrimination that may lessen the efficacy of psychosocial interventions (Rejeski \& Mihalko, 2001).

In our findings, we found out that participants with a higher wealth index had more improvement in anticipated stigma and discrimination compared with those with a wealth index. This is consistent with other studies (Perese, 2007). We speculate it is a reflection of better resources for coping with stigma.

On anticipated discrimination, our findings agree with another study (Ali et al. 2016) that gender modified the relationship between severity of Intellectual Disability (ID) and self-reported stigma in that male participants who had moderate ID were more likely to report stigma compared with females with moderate ID. This might explain why females were more likely to have higher improvements on the scores on 'stopping self' domain as compared with males. In addition, females display a greater response to psychotherapy than males, similar to what was found by Thornicroft et al. 2016). The reduction in stopping selfscores after the intervention was strongly associated with marital status with those who were married having better outcomes as compared with those who are single. We have already discussed the plausible explanation on the role of marital status.

The reduction in 'overcoming discrimination' was associated with employment status. Participants who are self-employed had more improvement in 'stopping self' scores compared with those that are unemployed. This may be partially explained by the fact that they have more resources than those unemployed. It can also be argued that being self-employed demonstrates possession of skills and that they can also apply in confronting stigma.

Being young was also associated with more improvement in 'stopping self' scores as explained above from the literature that older adults are likely to report more stigmatising experiences (Ali et al. 2016). In addition, older people may have other needs or risk factors for stigma and discrimination that may lessen the efficacy of psychosocial interventions (Rejeski \& Mihalko, 2001), which are part of mhGAP-IG. We have already demonstrated in the
Kenyan setting young people demonstrated a significant reduction in stigma post-intervention (Ndetei et al. 2016).

On 'overcoming discrimination', just like 'stopping self', being female, being married, being employed and being young was associated with better outcomes, however those with low wealth index had better outcomes as compared with those with higher wealth index.

The pattern of the different diagnoses reflect the clinical epidemiology of the cases identified for screening using mhGAP-IG, subsequently confirmed using the MINI-Plus. Overall, depression had better outcomes than all other conditions in all the domains except in treatment domain and for reasons explained below. It is not surprising that participants who were diagnosed with mania, psychosis, and epilepsy had better outcomes on the treatment domain as compared with those diagnosed with major depressive disorder since, unlike depression, the management of these conditions was symptom-oriented and best managed with psychotropics which have a faster effect than psychosocial intervention. Substance abuse and dementia which tend to take a chronic course with less indications for psychotropics and requiring much longer psychosocial intervention had worse outcomes compared with depression.

On the domain of 'unfair treatment', participants who were diagnosed with major depression had better outcomes as compared with those diagnosed with epilepsy, psychosis, mania/hypomania, alcohol abuse and suicide, for the same reasons already discussed above under the domain on unfair treatment. This is similar to the findings of Griffiths et al. (Griffiths et al. 2014) who found a better outcome for depression than for schizophrenia and overwhelming cultural stigma towards suicide and the complexity of treating more than one condition.

\section{Limitations}

(i) There were no control groups and therefore we cannot precisely tell whether the observed differences before and after intervention were due to mhGAP-IG interventions or other factors that affect the outcome. To mitigate this, we adjusted for all the measurable factors in the generalised linear mixed models during analysis. We recommend future studies with comparison groups. (ii) The participating centres were purposively sampled to suit the priorities of the County Government while at the same time representing all the levels of health care in the County. In mitigation, this was essentially a pilot study on the feasibility of WHO mhGAP-Intervention Guide in reducing 
experienced discrimination in mental disorders in a rural Kenyan setting.

\section{Conclusion}

The mhGAP-IG may be an effective tool for reduction of discrimination in clinical situations presided over by trained but supervised and supported clinicians in LIMCs. The 6-month's period between pre and post-tests is long enough to avoid recency (Oberauer, 2003; Morrison et al. 2014). However, we would recommend longer follow up in future studies to determine the longest possible time the outcomes would be sustained and what factors are at play. Outcomes are moderated by socio-demographic and economic characteristics, type of mental disorder, particular domains of stigma and emotional relationships especially within family members and possibly friends and workmates. To the best of our knowledge, this is the first study to report the use of mhGAP-IG to reduce discrimination in people living with mental disorders.

\section{Data sharing}

The data for this study will be made available upon written request to the corresponding author detailing the specific parts of the data to be shared and the intended purpose.

\section{Supplementary material}

The supplementary material for this article can be found at https://doi.org/10.1017/S2045796018000264

\section{Ethical standards}

Ethical approval for this study was obtained from Maseno University Ethics Review Committee (MU-ERC).

\section{Acknowledgements}

The Government of Makueni County for providing the necessary logistics for successful implementation of the study.

\section{Financial support}

This work was supported by Grand Challenges Canada (GCC), Grant \#0739-05

\section{Conflict of interest}

None.

\section{References}

Akena D, Joska J, Obuku EA, Amos T, Musisi S, Stein DJ (2012). Comparing the accuracy of brief versus long depression screening instruments which have been validated in low and middle income countries: a systematic review. BMC Psychiatry 12, 187.

Ali A, King M, Strydom A, Hassiotis A (2016). Self-reported stigma and its association with socio-demographic factors and physical disability in people with intellectual disabilities: results from a cross-sectional study in England. Social Psychiatry and Psychiatric Epidemiology 51, 465-474.

Barney LJ, Griffiths KM, Jorm AF, Christensen H (2006). Stigma about depression and its impact on help-seeking intentions. Australian $\mathcal{E}$ New Zealand Journal of Psychiatry 40, 51-54.

Brohan E, Clement S, Rose D, Sartorius N, Slade M, Thornicroft G (2013). Development and psychometric evaluation of the Discrimination and Stigma Scale (DISC). Psychiatry Research 208, 33-40.

Cohen J (1988). Statistical Power Analysis for the Behavioral Sciences, 2nd edn. Erlbaum Associates: Hillsdale.

Corrigan PW, Morris SB, Michaels PJ, Rafacz JD, Rüsch N (2012). Challenging the public stigma of mental illness: a meta-analysis of outcome studies. Psychiatric Services 63, 963-973.

Government of Makueni County (2017). https:// www.makueni.go.ke/

Griffiths KM, Carron-Arthur B, Parsons A, Reid R (2014). Effectiveness of programs for reducing the stigma associated with mental disorders. A meta-analysis of randomized controlled trials. World Psychiatry 13, 161175.

Gulliver A, Griffiths KM, Christensen H (2010). Perceived barriers and facilitators to mental health help-seeking in young people: a systematic review. BMC Psychiatry 10, 113.

Kenya National Bureau of Statistics (2010). Volume 1A-Population Distribution by Administrative Units. The 2009 Kenya Population and Housing Census.

Koschorke M, Padmavati R, Kumar S, Cohen A, Weiss HA, Chatterjee S, Pereira J, Naik S, John S, Dabholkar H (2014). Experiences of stigma and discrimination of people with schizophrenia in India. Social Science \& Medicine 123, 149-159.

Makueni County (2018). Department of Health Services. https://www.makueni.go.ke/ministers

Mendenhall E, Kohrt BA, Norris SA, Ndetei D, Prabhakaran D (2017). Non-communicable disease syndemics: poverty, depression, and diabetes among low-income populations. The Lancet 389, 951-963.

Morrison AB, Conway ARA, Chein JM (2014). Primacy and recency effects as indices of the focus of attention. Frontiers in Human Neuroscience 8.

Mutiso VN, Musyimi CW, Tomita A, Loeffen L, Burns JK, Ndetei DM (2017). Epidemiological patterns of mental disorders and stigma in a community household survey in urban slum and rural settings in Kenya. International Journal of Social Psychiatry 64, 120-129.

Nakimuli-Mpungu E, Bass JK, Alexandre P, Mills EJ, Musisi S, Ram M, Katabira E, Nachega JB (2012). 
Depression, alcohol use and adherence to antiretroviral therapy in sub-Saharan Africa: a systematic review. AIDS and Behavior 16, 2101-2118.

Ndetei DM, Mutiso V, Maraj A, Anderson KK, Musyimi C, McKenzie K (2016). Stigmatizing attitudes toward mental illness among primary school children in Kenya. Social Psychiatry and Psychiatric Epidemiology 51, 73-80.

Oberauer K (2003). Understanding serial position curves in short-term recognition and recall. Journal of Memory and Language 49, 469-483.

Perese EF (2007). Stigma, poverty, and victimization: roadblocks to recovery for individuals with severe mental illness. Journal of the American Psychiatric Nurses Association 13, 285-295.

Perlick DA, Rosenheck RA, Clarkin JF, Sirey JA, Salahi J, Struening EL, Link BG (2001). Stigma as a barrier to recovery: adverse effects of perceived stigma on social adaptation of persons diagnosed with bipolar affective disorder. Psychiatric Services 52, 1627-1632.

Rejeski WJ, Mihalko SL (2001). Physical activity and quality of life in older adults. The Journals of Gerontology Series A: Biological Sciences and Medical Sciences 56, 23-35.

Saxena S, Funk M, Chisholm D (2014). WHO's Mental Health Action Plan 2013-2020: what can psychiatrists do to facilitate its implementation? World Psychiatry 13, 107-109.

Sheehan DV, Lecrubier Y, Sheehan KH, Janavs J, Weiller E, Keskiner A, Schinka J, Knapp E, Sheehan MF, Dunbar
GC (1997). The validity of the mini international neuropsychiatric interview (MINI) according to the SCID-P and its reliability. European Psychiatry 12, 232-241.

Smits J, Steendijk R (2015). The international wealth index (IWI). Social Indicators Research 122, 65-85.

Thornicroft G, Brohan E, Rose D, Sartorius N, Leese M, Group IS (2009). Global pattern of experienced and anticipated discrimination against people with schizophrenia: a cross-sectional survey. The Lancet 373, 408-415.

Thornicroft G, Mehta N, Clement S, Evans-Lacko S, Doherty M, Rose D, Koschorke M, Shidhaye R, O'Reilly C, Henderson C (2016). Evidence for effective interventions to reduce mental-health-related stigma and discrimination. The Lancet 387, 1123-1132.

van Heyningen T, Myer L, Onah M, Tomlinson M, Field S, Honikman S (2016). Antenatal depression and adversity in urban South Africa. Journal of affective Disorders 203, 121-129.

Vyas S, Kumaranayake L (2006). Constructing socio-economic status indices: how to use principal components analysis. Health policy and Planning 21, 459-468.

W.H.O (2010). mhGAP Intervention Guide. World Health Organization: Geneva. 